East African Medical Journal Vol. 81 No 2 February 2004

DIAGNOSTIC VALUE OF PLAIN ABDOMINAL RADIOGRAPHS IN ACUTE APPENDICITIS IN CHILDREN

Z. Türkyilmaz, MD, Assistant Professor, Sönmez, MD, Assistant Professor, Ö. Konus, MD, Assistant Professor Department of Diagnostic Radiology,

B. Demirogullari, MD Assistant Professor, R. Karabulut, MD Instructor, Department of Paediatric Surgery, A. Can Basaklar MD., Professor, Department of

Paediatric Surgery, and N. Kale, MD., Department of Pediatric Surgery Gazi University Medical School, 06500, Besevler, Ankara, Turkey

Request for reprints to: Dr. Z. Türkyilmaz, Department of Paediatric Surgery, Gazi University Medical School, 06500, Besevler, Ankara, Turkey

\title{
DIAGNOSTIC VALUE OF PLAIN ABDOMINAL RADIOGRAPHS IN ACUTE APPENDICITIS IN CHILDREN
}

\author{
Z. TÜRKYILMAZ, K. SÖNMEZ, Ö. KONUS, B. DEMIROGULLARI, \\ R. KARABULUT, A. CAN BASAKLAR and N. KALE
}

\begin{abstract}
Objective: The plain film of the abdomen (PAX) is still utilised in the diagnosis of acute appendicitis (Aap). Aim of this study was to evaluate the value of PAX in the diagnosis of Aap in children, since it continues to be a controversial subject.

Design: A retrospective study.

Setting: Department of Paediatric Surgery, Gazi University Medical School.

Patients The histopathological diagnoses and PAX of 213 children (mean age 9-6 years) operated for acute right-lower quadrant pain were evaluated retrospectively. There were 181 patients with Aap and 32 with normal appendix.

Methods: The rate of detection of overall thirteen roentgenographic criteria defined in various reports in medical literature as indicating appendicitis were noted and compared with histopathological diagnoses. The PAX which revealed one or more of these signs in combination was considered to be positive for Aap. Data was analysed statistically and sensitivity, specificity and positive and negative predictive values of PAX in the diagnosis of Aap were determined.

Results: Roentgenographic sign(s) were detected in 170 (79\%) cases, 18 without Aap. The most frequent were lumbar scoliosis with left-sided convexity $(50 \%)$ and small intestinal air-fluid levels (32\%). In 39 cases, 25 with Aap, no sign(s) was detected. In all of the perforated cases, at least one of the determined criteria was seen. The percentage of roentgenographic signs found in cases with and without appendicitis was different significantly $(p<0.01)$. The negative predictive value of PAX in the diagnosis of acute appendicitis was $32.5 \%$ and positive predictive value was $89 \%$.

Conclusion: PAX could he helpful in diagnosis in children with suspected acute appendicitis.
\end{abstract}

\section{INTRODUCTION}

Acute appendicitis (Aap) is one of the leading causes of acute abdomen in all age groups, including childhood(1). Obtaining a good history and a careful physical examination is suggested to result in a correct diagnosis in $89-90 \%$ of all cases(2). However, the incidence of correct diagnosis could decrease considerably in preschool-age children, with reported negative laparotomy rates reaching as high as $70 \%(3)$. Plain abdominal film (PAX) is one of the most utilised imaging modalities that help to achieve the diagnosis of Aap which sometimes is hard to reach in childhood. This study investigates the relationship between roentgenographic findings suggestive of Aap with the histopathological confirmation in patients with a preoperative diagnosis of Aap. The findings that were sought are 13 in number, the highest number reported in the literature in adult and paediatric age groups.

\section{MATERIALS AND METHODS}

Two hundred and thirteen patients ( 84 girls, 129 boys) operated for Aap between January 1998-June 2001 in our clinic were included in the study. The mean age of the patients was 9.6 years (13 months-15 years). PAX of each of the patients were evaluated by one radiologist blinded to the clinicopathological diagnoses with respect to 13 roentgenographic signs reported to be related to Aap (1,48). The sought signs were as follows:

(i). Dilatation and air-fluid leves in the cecum indicating localized paralitic ileus.

(ii). Lumbar scoliosis with a left convexity resulting from right muscle spasm.

(iii). Blurring or loss of the right properitoneal fat stripe

(iv). Blunting in distal 1/3 lateral margin of the right psoas muscle (due to localized inflammation and edema).

(v). Presence of appendicoliths.

(vi). Small intestinal air-fluid levels.

(vii). Pneumoperitoneum (subdiaphragmatic free air).

(viii). Gas in appendix 
(ix). Increased soft tissue density in the pelvic and/or subphrenic region due to abscess formation.

(x). Separation of cecum from right properitoneal fat margin.

(xi). Blurring in the right sacroiliac joint compared with the left one due to right lower quadrant soft tissue mass.

(xii). Contour irregularity and oedema in the cecal wall.

(xiii). Colonic air-fluid levels.

The PAX which revealed one or more of these signs in combination was considered to be positive for Aap. The difference of positive and negative percentage of radiological signs in patients with Aap and in those with normal appendix (negative laparotomy) was compared by Pearson Chi-Square test. A p-value $<0.05$ was considered significant. In addition, positive and negative predictive value of PAX in the diagnosis Aap was calculated.

\section{RESULTS}

Evaluation of histopathological reports of 213 patients revealed that 32 had normal appendix and 181 had appendicitis ( 98 acute inflammated, 46 phlegmonated and 37 perforated ). There were no associated disorders in patients with normal appendix. Of these patients two developed diarrhoea in which no pathogenic organisms were isolated and one had histopathological findings suggestive of Yersinia enterocolitica infection in the biopsied mesenteric lymph node. One patient had a purpuric rush suggestive of Henoch-Schonlein purpura in the early postoperative period.

Rate of detection of the aforementioned radiological signs are shown in Table 1. In general, while 152 (84\%) of 181 patients with Aap had one or more related radiological signs, 25 of these patients (16\%) were without any signs. The most frequent signs were lumbar scoliosis $(\mathrm{n}=107,50 \%)$ and small intestinal air-fluid levels $(\mathrm{n}=68$, $32 \%)$. Eighteen $(56 \%)$ of 32 patients without Aap had at least one roentgenographic sign in their PAXs (Table 2). The percentage of PAX with positive signs in patients with Aap was statistically higher than from the percentage of those in patients without Aap $\left(p<0.01, x^{2}=12.252\right)$.

\section{Table 1}

The rate of detection of radiological signs in the patients

\begin{tabular}{lll}
\hline Radiological sign & $\begin{array}{l}\text { Patients with } \\
\text { Appendicitis (n=181) }\end{array}$ & $\begin{array}{l}\text { Patients with } \\
\text { Normal Appendix (n=32) }\end{array}$ \\
\hline Lumbar scoliosis & 89 & 18 \\
Small intestinal air-fluid levels & 68 & 8 \\
Blurring of right properitoneal fat stripe & 34 & 0 \\
Caecal localized ileus & 30 & 6 \\
Colonic air-fluid levels & 26 & 6 \\
Blurring of right sacroiliac joint & 17 & 4 \\
Blunting of right psoas muscle & 13 & 1 \\
Appendicoliths & 10 & 0 \\
Right lower quadrants soft tissue mass & 6 & 1 \\
Caecal separation from properitoneal fat & 6 & 2 \\
Caecal deformity & 5 & 0 \\
Pneumoperitoneum & 3 & 0 \\
Gas in appendix & 1 & 0 \\
\hline
\end{tabular}

Table 2

The rate of positive and negative radiographs with histopathological diagnosis

\begin{tabular}{|c|c|c|c|c|}
\hline \multirow[t]{2}{*}{ Radiological sign } & \multicolumn{4}{|c|}{ Histopathological findings of appendix } \\
\hline & Normal appendix & Acute inflammed & Phlegmonated & Perforated \\
\hline $\begin{array}{l}\text { Present } \\
\text { (Positive) } n=170 \\
\text { Absent } \\
\text { (Negative) } n=43\end{array}$ & $\begin{array}{l}18 \\
(56 \%) \\
14 \\
(44 \%)\end{array}$ & $\begin{array}{l}77 \\
(78 \%) \\
21 \\
(22 \%)\end{array}$ & $\begin{array}{l}38 \\
(82 \%) \\
8 \\
(18 \%)\end{array}$ & $\begin{array}{l}37 \\
(100 \%) \\
0 \\
(0 \%)\end{array}$ \\
\hline Total $(n=213)$ & 32 & 98 & 46 & 37 \\
\hline
\end{tabular}


Similarly, the percentage of PAX without any radiological signs in the patients having Aap was statistically less than from the percentage of those in patients with a normal appendix $(\mathrm{p}<0.01)$.

Number of cases with PAX with more than one positive radiological sign was $120(56 \%)$ and 109 of these had Aap; thus resulting in a positive predictive value of $90 \%$, sensitivity of $71 \%$ and a specificity of $38 \%$. The number of cases with PAX with only one positive sign was 50 and 43 of these had Aap. PAX with only one positive sign was associated with a positive predictive value of $86 \%$, sensitivity of $28 \%$ and specificity of $61 \%$. The ratios of Aap patients with multiple positive signs in PAX compared with those of only one positive sign were similar statistically ( $p>0.05)$. All cases with perforated appendicitis had at least one sign in their PAX.

Positive predictive value of PAX in the diagnosis of Aap was calculated as $89 \%$ with a sensitivity of $84 \%$ and negative predictive value as $32.5 \%$ with a specificity of $44 \%$.

\section{DISCUSSION}

Appendicoliths-calcified faecaloid material in the appendix, the first described roentgenographic sign to indicate appendicitis, was reported by Weisflog in 1906(9). This sign has led to generally consistent articles related with aetiopathogenesis, diagnosis and clinical course of the disease $(1,7,8,10)$. The first detailed study was reported by Steinhert et al. by examining the PAX of 104 patients with histopathologically proven appendicitis(8).

A number of roentgenographic signs indicative of appendicitis have been described. Although many authors have proposed that these signs are not specific to Aap, PAX are obtained in almost all of the patients admitted with a clinical picture suggestive of Aap.

In this study, most frequent roentgenographic signs detected were, in decreasing order lumbar scoliosis, small intestinal air-fluid levels and blurring of right properitoneal fat stripe. In this series, lumbar scoliosis was found in $107(50 \%)$ patients with histologically proven Aap. This number is consistent with reported incidence of $50 \%$ in the literature(9). However, its detection in $18(56 \%)$ children with normal appendix decreases the diagnostic value of this sign. The ratios of caecal and small intestinal air-fluid levels which are proposed to arise from localized paralytic ileus were $16 \%(n=30)$ and $37.5 \%(n=68)$ respectively. These two signs in combination with colonic air-fluid levels were detected in the PAX of 90 (48\%) Aap patients in this series. The ratio of detecting air-fluid levels in small and large intestines roentgenographically ranges between $30-80 \%$ in the literature $(9,11)$. This sign is reported as one of the most reliable findings in the diagnosis of Aap; however we observed that it was present in $25 \%$ of negative laparotomy cases in our series. This falsepositive ratio of this sign could be related with viral infections considered to play a role in non-specific abdominal pain(3), especially in children. It should also be noted that intestinal air-fluid levels were reported in an incidence of $11.5 \%$ in PAX obtained from 200 healthy individuals(11). When we studied whether combination of the signs had any implications on the positive predictive value, we found that it was the same for PAX both with multiple signs and with only one sign ( $p>0.05)$. Thus, PAX with more than one sign is not superior to PAX with only one sign to be suggestive of Aap, given that all of the mentioned radiological signs are sought for while evaluating the graphies.

We could detect appendicolith only in $10(5.5 \%)$ PAX. This number is consistent with the reported incidence of $7-12 \%$ in large series. Its presence has been reported in an incidence of as high as $50 \%$ in an article on childhood cases (8). We observed that all patients with appendicolith in their PAX had appendicitis, four Aap and six perforated. Its presence is therefore strongly suggestive of acute appendicitis in clinically suspected cases.

The relatively high rate of $84 \%$ of positive radiologic signs detected in clinicopathologically proven cases of Aap in this study contrast to ranges of 50$72 \%$ reported in the literature $(8,11)$. This higher rate could he due to relatively high number of radiologic signs that wore sought for compared to other reports. We also observed that in the advanced stages of the disease radiographic signs were detected in an increased rate. At least one sign was seen in all of the perforated cases in this present study. A positive predictive value of $89 \%$ of PAX in the diagnosis of Aap obtained in our study could be considered as a justification of its utilization in patients thought to have Aap. Even if perforated cases where a clinical diagnosis could be reached rather easily are excluded, the positive predictive value is observed to stay in a high ratio of $70 \%$, probably due to the great number of radiological signs that were looked for. This difference in the value could be due to retrocaecal localization of the appendix. In a postmortem study it has been reported that appendix localizes in this site in $65 \%$ of specimens(12).

The fact that there was a significant statistical difference between the rate of PAX signs detected in negative laparotomy patients without Aap (56\%), compared with those of having Aap (84\%) reveals the usefulness of this modality as a support in the diagnosis of Aap $(\mathrm{p}<0.01)$. Also, the negative predictive value of PAX in the diagnosis of Aap was found to be $32.5 \%$ in this study. Thus, one can consider this technique helpful in excluding one third of the patients without Aap and save them from undergoing a negative laparotomy, at least in childhood. Furthermore, in case that there exists a consideration of other abdominal diseases such as urinary stones or bowel obstruction, PAX could be helpful in ruling out a number of those pathological conditions. 
A plain abdominal film still has a role in the investigation of acute appendicitis. Even more refined techniques other than PAX undertaken to help in achieving this rather difficult diagnosis could fail in childhood, as evidenced in some reports $(13,14)$. Ultrasonographic examination (USG) of the abdomen which is one of the most utilised current diagnostic modality is not without some drawbacks in this age group. The diagnostic value of this modality is considered to decline in perforated appendix which is seen in higher rates in childhood(13,14). On the contrary, as could be seen in our series, the diagnostic value of PAX increases as this surgical event progresses resulting in higher positive predictive values (Table 2). Although the main diagnostic tool of Aap in childhood is a meticulous physical examination and taking a good history, PAX could still be helpful in suspicious cases.

\section{REFERENCES}

1. Raffensperger, J.G., Seeler, R.A. and Moncada, R. The Acute Abdomen in Infancy and Childhood. Blackwell, Oxford, 1970.

2. Surana, R., O'Donnell, B. and Atwell, J.D. (Eds). Acute abdominal pain. Paediatric Surgery. 1998; London, Arnold. PP402-421.

3. Paajanen, H. and Somppi, E. Early childhood appendicitis is still a difficult diagnosis. Acta Paediatr. 1996; 85: 459-462.

4. Fee, H A, Jones, P. C, Kadell, B and O'Connell, T.X Radiologic diagnosis of appendicitis. Arch. Surg. 1977; 112:742-744.
5. Campbell, J.P.M. and Gunn, A.A. Plain abdominal radiographs and abdominal pain. Brit. J. Surg. 1988; 75:554-556.

6. Mirvis, S.E., Young, L.W.K., Keramati, B., McCrea, E.S. and Tarr, R. Plain film evaluation of patients with abdominal pain: are three radiographs necessary? Amer. J. Rad. 1986; 147:501-503.

7. Shaw, R.E. Appendix calculi and acute appendicitis. Brit. J. Surg. 1965; 52:451-459.

8. Shimkin, P.M. Radiology of acute appendicitis, Commentary. Amer. J. Rad. 1978; 130:1001-1004.

9. Olutola, P.S. Plain film radiographic diagnosis of acute appendicitis: an evaluation of the signs. Can. Assoc. Radiol. J. 1988; 39:254-256.

10. Nitecki, S. Karmeli, R. and Sarr, M.G. Appendiceal calculi and fecaliths as indications for appendectorny. Surg. Gynecol. Obstet. 1990; 171:185-188.

11. Graham, A.D. and Johnson, H.F. The incidence of radiographic findings in acute appendicitis compared to 200 normal abdomens. Milit. Med. 1966; 131:272-276.

12. Donellan, W.L., Schafer, J.C. Donellan, W.L., . Burrington, J.D. and Kimura, K. (Eds). Acute and recurrent appendicitis. Abdominal Surgery of Infancy and Childhood. Harwood academic publishers, Luxembourg. 1996; 45:1-24

13. Wong, M.L., Casey, S.O., Leonidas, J.C., Elkowitz, S.S. and Becker, J. Sonographic diagnosis of acute appendicitis in children. J. Pediatr. Surg. 1994; 29:1356-1360.

14. Chesbrough, R.M., Burkhard, T.K., Balsara, Z.N., Goff, W.B. II and Davis, D.J. Self-localization in US of appendicitis: an addition to graded compression. Radiology. 1993; 187:349-351. 